\title{
Uso do grafeno e nióbio na prática médica: uma revisão narrativa de literatura
}

\author{
Use of graphene and niobium in medical practice: a narrative literature review \\ Uso de grafeno y niobio en la práctica médica: una revisión narrativa de la literatura
}

\author{
Bárbara Queiroz de Figueiredo \\ ORCID: https://orcid.org/0000-0003-1630-4597 \\ Centro Universitário de Patos de Minas, Brasil \\ E-mail: barbarafigueiredo@unipam.edu.br \\ Álvaro Peixoto de Morais \\ ORCID: https://orcid.org/0000-0002-1309-0012 \\ Universidade Federal de São Paulo, Brasil \\ E-mail: alvaro.pm@hotmail.com \\ Ana Clara Viana Soares Brito \\ ORCID: https://orcid.org/0000-0001-5747-4280 \\ Centro Universitário Uninovafapi, Brasil \\ E-mail: anaclaravsb@hotmail.com \\ Dieison Danrlei Roehrs \\ ORCID: https://orcid.org/0000-0003-2919-9765 \\ Centro Universitário de Goiatuba, Brasil \\ E-mail: dieisondanrlei1@ hotmail.com \\ Heitor Laborão Carneiro \\ ORCID: https://orcid.org/0000-0001-5690-7101 \\ Pontifícia Universidade Católica de Goiás, Brasil \\ Email: heitorcolt@hotmail.com \\ Isabelle Gomes de Sousa \\ ORCID: https://orcid.org/0000-0002-0067-019X \\ Centro Universitário Uninovafapi, Brasil \\ E-mail: isabellegmss@hotmail.com \\ Letícia de Oliveira Araújo \\ ORCID: https://orcid.org/0000-0002-3457-4235 \\ Centro Universitário de Patos de Minas, Brasil \\ E-mail: leticiaoaraujo21@gmail.com \\ Lorena Martins Nagata \\ ORCID: https://orcid.org/0000-0003-1487-6436 \\ Centro Universitário de Goiatuba, Brasil \\ E-mail: lorena-mvet@live.com \\ Lunalva Gabrielli Veras Sousa \\ ORCID: https://orcid.org/0000-0001-5181-5371 \\ Centro Universitário Uninovafapi, Brasil \\ E-mail: veraslunalva@gmail.com \\ Maria Jacilene de Araújo Gomes \\ ORCID: https://orcid.org/0000-0002-6774-9097 \\ Instituto Master de Ensino Presidente Antônio Carlos, Brasil \\ E-mail: jacilene_araujo@hotmail.com \\ Melina Fonseca Maia França Coury Alves \\ ORCID: https://orcid.org/0000-0002-1403-8435 \\ Centro Universitário de Patos de Minas, Brasil \\ E-mail: meeelcoury@gmail.com
}

\begin{abstract}
Resumo
Introdução: Os chamados nanomateriais são considerados por muitos, materiais que possuem sua estrutura restrita a dimensões de 1 a $100 \mathrm{~nm}$. Os nanomateriais apresentam uma extensa faixa de aplicações como na biomedicina, na área de alimentos e agricultura, drogas e vacinas e principalmente na catálise. Objetivo: evidenciar as aplicações dos nanomateriais grafeno e nióbio na medicina, ressaltando seus resultados promissores nesse campo. Metodologia: Trata-se de uma pesquisa descritiva do tipo revisão narrativa da literatura. A pesquisa foi realizada através do acesso online nas bases de dados National Library of Medicine (PubMed MEDLINE), Scientific Electronic Library Online (Scielo), Cochrane Database of Systematic Reviews (CDSR), Google Scholar, Biblioteca Virtual em Saúde (BVS) e EBSCO Information Services, no mês de novembro de 2021. Resultados e discussão: O óxido de grafeno reduzido tem se mostrado um excelente agente fototérmico, permitindo a eliminação eficiente de tumores em experimentos in vivo, bem como, devido a excelente condutividade elétrica do grafeno promete melhorar a conversão das sinapses em movimento. Além disso, o uso de nióbio cresce no campo da medicina como elemento de liga para aumento de
\end{abstract}


resistência mecânica para implantes ortopédicos biocompatíveis. Considerações finais: Assim, é possível afirmar que são muitos os benefícios que o grafeno e o nióbio, interligados com as nanotecnologias, gerarão à humanidade, e, principalmente aos avanços da medicina.

Palavras-chave: Nanomateriais; Aplicações; Medicina; Nióbio; Grafeno.

\begin{abstract}
Introduction: The so-called nanomaterials are considered by many, materials that have their structure restricted to dimensions from 1 to $100 \mathrm{~nm}$. Nanomaterials have a wide range of applications in biomedicine, food and agriculture, drugs and vaccines, and especially in catalysis. Objective: to show the applications of graphene and niobium nanomaterials in medicine, highlighting their promising results in this field. Methodology: This is a descriptive research of the narrative literature review type. The search was carried out through online access in the National Library of Medicine (PubMed MEDLINE), Scientific Electronic Library Online (Scielo), Cochrane Database of Systematic Reviews (CDSR), Google Scholar, Virtual Health Library (BVS) and EBSCO databases Information Services, November 2021. Results and discussion: Reduced graphene oxide has been shown to be an excellent photothermal agent, allowing the efficient elimination of tumors in in vivo experiments, as well as, due to the excellent electrical conductivity of graphene, it promises to improve the conversion of synapses into motion. Furthermore, the use of niobium is growing in the medical field as an alloying element to increase the mechanical strength of biocompatible orthopedic implants. Final considerations: Thus, it is possible to say that there are many benefits that graphene and niobium, interconnected with nanotechnology, will generate to humanity, and especially to medical advances.
\end{abstract}

Keywords: Nanomaterials; Applications; Medicine; Niobium; Graphene.

\title{
Resumen
}

Introducción: Los denominados nanomateriales son considerados por muchos, materiales que tienen su estructura restringida a dimensiones de $1 \mathrm{a} 100 \mathrm{~nm}$. Los nanomateriales tienen una amplia gama de aplicaciones en biomedicina, alimentación y agricultura, medicamentos y vacunas, y especialmente en catálisis. Objetivo: mostrar las aplicaciones de los nanomateriales de grafeno y niobio en medicina, destacando sus prometedores resultados en este campo. Metodología: Se trata de una investigación descriptiva del tipo revisión de literatura narrativa. La búsqueda se realizó mediante acceso online en la Biblioteca Nacional de Medicina (PubMed MEDLINE), Scientific Electronic Library Online (Scielo), Cochrane Database of Systematic Reviews (CDSR), Google Scholar, Virtual Health Library (BVS) y bases de datos EBSCO Information Services. Noviembre de 2021. Resultados y discusión: Se ha demostrado que el óxido de grafeno reducido es un excelente agente fototérmico, permitiendo la eliminación eficiente de tumores en experimentos in vivo, así como, debido a la excelente conductividad eléctrica del grafeno, promete mejorar la conversión de sinapsis en movimiento. Además, el uso de niobio está creciendo en el campo médico como un elemento de aleación para aumentar la resistencia mecánica de los implantes ortopédicos biocompatibles. Consideraciones finales: Así, se puede decir que son muchos los beneficios que el grafeno y el niobio, interconectados con la nanotecnología, generarán a la humanidad, y especialmente a los avances médicos.

Palabras clave: Nanomateriales; Aplicaciones; Medicamento; Niobio; Grafeno.

\section{Introdução}

Os chamados nanomateriais são considerados por muitos, materiais que possuem sua estrutura restrita a dimensões de 1 a 100 nm. Porém, essa definição é pouco importante, uma vez que as propriedades evoluem e não há argumento físico para essa classificação. De uma forma geral, são as propriedades dos materiais que regem esse conceito e não necessariamente as dimensões das partículas. O estudo de tais materiais ganhou importância considerável no final do século XX, o que levou ao aparecimento de um grande ramo da ciência conhecido como "Nanociência e Nanotecnologia". Assim, os nanomateriais apresentam uma extensa faixa de aplicações como na biomedicina, na área de alimentos e agricultura, drogas e vacinas e principalmente na catálise (Alves, 2013).

O grafeno é uma folha plana de átomos de carbono compactados em uma grade de duas dimensões com espessura de apenas um átomo, reunidos em uma estrutura cristalina hexagonal. A folha de grafeno pode formar uma esfera (fulereno) ou um tubo (nanotubo). Se muitas dessas folhas forem empilhadas, resultará num grafite tridimensional. O uso do termo "camada de grafeno" é também considerado para a terminologia geral dos carbonos. O grafeno, que tem a espessura de um átomo de carbono, é um dos materiais mais revolucionários que se acredita ter desenvolvido, devido as suas excelentes propriedades 
mecânicas, elétricas, térmicas, ópticas, entre outras. Estas propriedades sugerem que o grafeno substituirá muitos materiais em diversas aplicações (Jain et al., 2018).

Já o nióbio está presente na natureza na forma de pirocloro natural $[(\mathrm{Na}, \mathrm{Ca}) 2 \mathrm{Nb} 2 \mathrm{O} 6(\mathrm{OH}, \mathrm{F})]$ e columbita-tantalita [(Ta,Nb)2O6)], que estão associadas às rochas pegmatitas. Suas diversas formas estruturais e fases cristalinas relatadas na literatura são consideradas complexas e possuem formas polimórficas: pseudohexagonal, ortorrômbico e monoclínico, conferindo a esses materiais diferentes atividades catalíticas. Também contém propriedades promissoras para aplicações ambientais como caráter hipoalergênico, citotoxidade e alta estabilidade termodinâmica e, por isso, pode ser utilizado não apenas na química, como na biologia, na genética e na medicina (Toma, 2016). Sob essa perspectiva, o objetivo deste estudo foi de evidenciar as aplicações dos nanomateriais grafeno e nióbio na medicina, ressaltando seus resultados promissores nesse campo.

\section{Metodologia}

Trata-se de uma pesquisa descritiva do tipo revisão narrativa da literatura, que buscou evidenciar as aplicações dos nanomateriais grafeno e nióbio na medicina, ressaltando seus resultados promissores nesse campo. A pesquisa foi realizada através do acesso online nas bases de dados National Library of Medicine (PubMed MEDLINE), Scientific Electronic Library Online (Scielo), Cochrane Database of Systematic Reviews (CDSR), Google Scholar, Biblioteca Virtual em Saúde (BVS) e EBSCO Information Services, no mês de novembro de 2021. Para a busca das obras foram utilizadas as palavras-chaves presentes nos descritores em Ciências da Saúde (DeCS): em inglês: "nanomaterials", "medicine", "niobium", "graphene", "nantubes", "applications" e em português: "nanomateriais", "medicina", "nióbio", "grafeno", "nanotubos", "aplicações".

Como critérios de inclusão, foram considerados artigos originais, que abordassem o tema pesquisado e permitissem acesso integral ao conteúdo do estudo, publicados no período de 2007 a 2021, em inglês e português. O critério de exclusão foi imposto naqueles trabalhos que não estavam em inglês ou português, que não tinham passado por processo de Peer-View e que não abordassem o tema da pesquisa. A estratégia de seleção dos artigos seguiu as seguintes etapas: busca nas bases de dados selecionadas; leitura dos títulos de todos os artigos encontrados e exclusão daqueles que não abordavam o assunto; leitura crítica dos resumos dos artigos e leitura na íntegra dos artigos selecionados nas etapas anteriores. Assim, totalizaram-se 23 artigos científicos para a revisão narrativa da literatura, com os descritores apresentados acima.

\section{Resultados e Discussão}

\subsection{Grafeno}

Nanomateriais de carbono com ligações $\mathrm{sp}^{2}$ possuem propriedades mecânicas, eletrônicas, óticas e químicas únicas e têm se mostrado interessantes para muitas aplicações. Entre eles, os nanotubos de carbono (nanoestruturas 1D de carbono na forma de um tubo) e os grafenos (folhas de carbono 2D) são os que mais têm chamado atenção e estudos recentes têm mostrado o elevado potencial destes materiais para aplicações em medicina. Eles têm sido amplamente investigados para aplicações em biossensores, engenharia de tecidos, drug-delivery, imageamento molecular, entre outros. Além disso, nanotubos de carbono e grafenos possuem forte absorção ótica na região do infravermelho próximo, tornando-os materiais promissores para utilização em fototermia (Geim et al., 2007).

Com isso, os nanotubos de carbono têm sido amplamente utilizados como plataformas na fabricação de biossensores para detectar biomoléculas. Além disso, estudos têm mostrado que a funcionalização deste material permite sua atuação como moléculas carreadoras de medicamentos para aplicações em drug delivery e tem sido empregado com sucesso no tratamento de câncer, por exemplo, nanotubos de carbono funcionalizados com polietileno glicol e conjugados com o quimioterápico 
paclitaxel proporcionaram maior eficácia na supressão do crescimento do câncer de mama. Isto se deve, principalmente, ao maior acumulo do quimioterápico na região do câncer quando conjugado com os nanotubos (Geim 2009).

Recentemente, um número crescente de trabalhos tem explorado o potencial do grafeno para aplicações biomédicas. Por possuir uma estrutura similar as dos nanotubos de carbono, grafenos também podem ser utilizados como carreadores de medicamentos e no tratamento contra o câncer. Por exemplo, óxido de grafeno reduzido tem se mostrado um excelente agente fototérmico, permitindo a eliminação eficiente de tumores em experimentos in vivo. Em outro estudo, óxido de grafeno funcionalizado com polietilenoimina (PEI) foi conjugado com RNA de interferência e com o antitumoral doxorrucibina. Esta entrega simultânea permitiu um aumento significativo da eficiência na quimioterapia (Novoselov et al., 2012). Além disso, o grafeno também tem sido conjugado com componentes de imageamento e terapêuticos, formando materiais teranósticos. Um estudo recente mostra a funcionalização de óxido de grafeno com nanopartículas de óxido de ferro e o polímero polietileno glicol (PEG) para adicionar propriedades magnéticas e melhorar a biocompatibilidade, respectivamente (Prado et al., 2017).

Ademais, grupos de pesquisa estão desenvolvendo preservativos à base de grafeno, o que poderia conduzir mais calor que o látex, bem como pretende reduzir a espessura de $0,07 \mathrm{~mm}$ atuais para 0,04 $\mathrm{mm}$. Além disso, pesquisadores criaram uma lente de contato capaz de captar todo o espectro de raios vermelhos e, com isso, o usuário seria capaz de enxergar no escuro e devolver a visão a pacientes por meio de implantes de retina de grafeno (Hu et al., 2017). Em testes realizados com animais, Jain et al. (2018) alcançaram resultados surpreendentes no combate ao glioma, um tipo de tumor cerebral. Ao isolar a célula cancerosa com uma película de grafeno, os pesquisadores conseguiram interromper o fornecimento de oxigênio e nutrientes e, assim, matar de fome a massa cancerosa. Também, a excelente condutividade elétrica do grafeno promete melhorar a conversão das sinapses em movimento (Tang et al., 2020).

\subsection{Nióbio}

$\mathrm{Na}$ última década as aplicações de nióbio aumentaram constantemente em vários segmentos, aproveitando suas características: aços microligados, super ligas, implantes médicos, supercondutores e condensadores (Vasconcelos et al., 2019). A procura de novos materiais metálicos, aplicados em implantes ortopédicos, tais como os aços inoxidáveis austeníticos, tem se intensificado nestes últimos anos. Este fato deve-se às diferentes falhas que os mesmos ainda apresentam e que são de natureza fisiológica (biocompatibilidade), mecânica (resistência) e química (corrosão) (Lopes et al., 2015). Com isso, o uso de nióbio cresce no campo da medicina como elemento de liga para aumento de resistência mecânica para implantes ortopédicos biocompatíveis (Li et al., 2011).

Em pesquisa de Shapira et al. (2020), que teve como objetivo investigar o comportamento de células humanas semelhantes a osteoblastos cultivadas, em todos os grupos as células proliferaram rapidamente entre os dias 1 e 3 e, em seguida, estabilizaram. A maioria dos implantes de titânio e ligas de titânio atualmente disponíveis em aplicações clínicas são densos. Embora alguns métodos, como o tratamento de superfície, possam ser aplicados para aumentar a área de contato, esses métodos produzem certos efeitos na integração óssea entre os implantes e o osso. Ademais, pesquisa de Wang et al. (2010) já havia descoberto que a taxa de osseointegração da liga de revestimento de titânio e nióbio ( $\mathrm{TiNb}$ ) era melhor do que a liga de revestimento de titânio (Ti), o que indiretamente provou a importância do nióbio misturado com titânio.

No entanto, o tecido ósseo só pode se estender ao campo da superfície do implante e não ao interior dos implantes. A fixação biológica não é alcançada quando a estabilidade a longo prazo não é garantida. Sob essa perspectiva, os ensaios in vivo e in vitro demonstraram que a presença do óxido de nióbio potencializou as propriedades osteoestimuladora do biovidro (Cavalcanti et al., 2013). Assim, além de biocompatível, ele passou a ser também bioativo, favorecendo a regeneração do 
tecido ósseo. Ou seja, no caso do uso do material por parte da medicina regenerativa, os ganhos poderão ser significativos (Munroe et al., 2009).

Dada a diferença nas propriedades mecânicas, a liga do tipo denso provoca proteção contra estresse após a implantação no corpo, o que acaba levando à reabsorção óssea (Pytlicek et al., 2019). Muitos estudos mostraram que o excesso de perda óssea influencia o efeito de longo prazo dos implantes e leva ao deslocamento do implante, afrouxamento asséptico, fratura ao redor da prótese e aumento da dificuldade de cirurgia de revisão (Santos et al., 2019). Assim, o nióbio pode reduzir a temperatura de transição para a fase beta, aumentar a zona de duas fases alfa e beta e melhorar a usinabilidade e a resistência à corrosão da liga de titânio. Ademais, notou-se que todas as ligas porosas de titânio-nióbio mostraram boa biocompatibilidade, independentemente da porcentagem de porosidade (Shareena et al., 2018).

Ademais, recentemente, pesquisadores da Universidade Federal de Minas Gerais (UFMG) criaram uma solução à base de nióbio capaz de proteger diferentes tipos de superfície do SARS-CoV-2, por até 24 horas. Aplicada na forma de gel ou líquido spray, a solução tem ação prolongada para limpeza e desinfecção das mãos e não causa reações adversas, como sensação de ressecamento da pele. O produto também se mostrou ativo na proteção de superfícies em ambiente doméstico e equipamentos e utensílios nos ambientes médico e odontológico (Maroli 2021).

\subsection{Principais preocupações da aplicação de nanomateriais em medicina}

Para uma aplicação com alta sensibilidade e seletividade em sistemas diagnósticos e terapêuticos, os nanomateriais devem estar combinados com biomoléculas ainda mais específicas, por exemplo, sistemas antígeno/anticorpo, enzima/substrato, receptores ou proteínas de membrana, sequências de DNA, RNA ou aptâmeros, cofatores, enfim, uma variedade de biomoléculas como descrito anteriormente. Além desses fatores, um importante parâmetro que deve ser levado em consideração quando um sistema diagnóstico e/ou terapêutico é desenvolvido é a biodisponibilidade no meio biológico (Ferreira et al., 2009).

Apesar da funcionalização de nanomateriais com moléculas específicas, a biodispersidade e disponibilidade de nanomateriais em sistemas biológicos ainda são reduzidas. Com isso, um novo termo foi estabelecido para se referir a esses materiais, os chamados nano-objetos e seus agregados e aglomerados, do inglês, "nano-objects their agglomerates and aggregates" (NOAA) sem alterar totalmente suas dimensões na nanoescala, podendo ou não possuir as mesmas características de um nanomaterial totalmente disperso (Toma, 2016).

Além disso, devido às suas dimensões reduzidas, as nanopartículas podem penetrar em diversas regiões do organismo de um indivíduo que participa da fabricação, manipulação ou mesmo do uso destas como diagnósticas ou terapia em nanomedicina, isto é, por meio da absorção/adsorção desses nanomateriais no uso como creme para pele, via oral, ou por inalação. Porém, essa entrada no sistema biológico depende de diversos fatores como composição química da superfície, propriedades físico-químicas, tamanho e forma, capacidade de agregação ou aglomeração, ou mesmo a funcionalização com biomoléculas específicas (Makvandi et al., 2020). Outro fator importante são as doses, e o questionamento de até que ponto as doses administradas não demonstram efeitos tóxicos, ou quanto tempo esse nanomaterial fica disponível dentro do organismo até ser completamente eliminado, e como será essa eliminação entram em xeque (Tang et al., 2020). Como os nanomateriais possuem diferentes tamanhos e funcionalizações, cada um poderá apresentar um mecanismo diferente de entrada na célula (Alves, 2013).

Outrossim, um estudo realizado com nanopartículas esféricas de poliestireno com dimensões de $20 \mathrm{~nm}$ sugere que essas entram nas células através da membrana em uma passagem direta sem a necessidade de mecanismos de transporte específicos, seguido da distribuição por todo o citoplasma e ligando-se a várias bioestruturas do citoesqueleto (Stróz et al., 2018). Ou seja, compreender os mecanismos de entrada e saída das células, assim como assegurar a estabilidade das 
nanopartículas, principalmente as propriedades de superfície, será fundamental para garantir a segurança e melhor aproveitamento de suas funções.

\section{Considerações Finais}

É possível afirmar que são muitos os benefícios que o grafeno e o nióbio, interligados com as nanotecnologias, gerarão à humanidade, e, principalmente aos avanços da medicina, que vão desde a formação de profissionais, desenvolvimento de novos produtos e processos, melhoria na qualidade de vida, materiais com novas propriedades, até o desenvolvimento científico, tecnológico, econômico e social.

\section{Referências}

Alves, O. L. (2013). Nanotecnologias: Elas Já Estão Entre Nós. Revista Ciência e Cultura, 65 (3), 22-27.

Cavalcanti, R. M. et al. (2013). Characterization of ZSM-5 modified with niobium pentoxide: The study of thiophene adsorption. Journal of the Brazilian Chemical Society, 24 (1), 40-50.

Ferreira, H. S., et al. (2009). Nanotecnologia: Aspectos gerais e potencial de aplicação em catálise. Química Nova, 32 (7), $1860-1870$.

Geim A. K., et al. (2007). The rise of graphene. Nature Mater, 6 (5), 183-191.

Geim, A. K. (2009). Graphene: status and prospects. Science, 324 (33), 1530 -1543.

Hu, M., et al. (2017). Graphene-Based Nanomaterials for Catalysis. Industrial and Engineering Chemistry Research, 56 (13), $3477-3502$.

Jain, A. et al. (2018). Nanomaterials in food and agriculture: An overview on their safety concerns and regulatory issues. Critical Reviews in Food Science and Nutrition, 58 (2), 297-317.

Li, H., et al. (2011). Remarkable biocompatibility enhancement of porous NiTi alloys by a new surface modification approach: in-situ nitriding and in vitro and in vivo evaluation. J Biomed Mater Res., 99 (4), 544-553.

Lopes, O. F. et al. (2015). Óxidos de nióbio: Uma visão sobre a síntese do Nb2O5 e sua aplicação em fotocatálise heterogênea. Química Nova, 38 (1), 106117.

Makvandi, P. et al. (2020). Metal-Based Nanomaterials in Biomedical Applications: Antimicrobial Activity and Cytotoxicity Aspects. Advanced Functional Materials, 30 (22), 1-8.

Maroli, C. (2021). Caracterização de nanoestruturas de óxido de nióbio para aplicação em fotocatálise heterogênea. TCC (graduação) - Universidade Federal de Santa Catarina. Centro de Ciências Físicas e Matemáticas. Curso de Química, 1-86.

Munroe, N., et al. (2009). Enhanced Biocompatibility of Porous Nitinol. J Mater Eng Perform., 18 (6), 765-767.

Novoselov, K.S. et al. (2012). A roadmap for graphene. Nature, 190 (5), 192-200.

Prado, N. T., et al. (2017). Nanostructured niobium oxide synthetized by a new route using hydrothermal treatment: High efficiency in oxidation reactions. Applied Catalysis B: Environmental, 205 (5), 481-488.

Pytlicek, Z. et al. (2019). On-chip sensor solution for hydrogen gas detection with the anodic niobium-oxide nanorod arrays. Sensors and Actuators, 284 (12), $723-735$.

Santos, A. J. et al. (2019). Niobium oxide catalysts as emerging material for textile wastewater reuse: Photocatalytic decolorization of azo dyes. Catalysts, 9 (12), 56-70.

Shapira L., et al. (2020). Efeito de uma liga de titânio contendo nióbio no comportamento de osteoblastos em cultura. Pesquisa Clínica de Implantes Orais, 20 (6), 578-582.

Shareena, T. P. D et al. (2018). A Review on Graphene-Based Nanomaterials in Biomedical Applications and Risks in Environment and Health. Nano-Micro Letters, 10 (3), 1-34.

Stróz, A., et al. (2018). Electrochemical Formation of Self Organized Nanotubular Oxide Layers on Niobium (Review). Current Nanoscience, 15 (1), $42-48$.

Tang, Z. et al. (2020). Phosphorus Science-Oriented Design and Synthesis of Multifunctional Nanomaterials for Biomedical Applications. Matter, 2 (2), 297322.

Toma, H. (2016). Nanotecnologia Molecular - Materiais e Dispositivos. Edgard Blü ed. 1-67.

Vasconcelos Y., et al. (2019). O polêmico nióbio. Revista Pesquisa FAPESP, 20 (277), 63-69.

Wang, X., et al. (2010). Biomimetic modification of porous TiNbZr alloy scaffold for bone tissue engineering. Tissue Eng Part., 56 (6) $309-316$. 